Infect Dis Clin North Am. 2018 September ; 32(3): 667-685. doi:10.1016/j.idc.2018.04.007.

\title{
Endemic Mycoses in Solid Organ Transplant Recipients
}

\author{
Jeremy S. Nel, MD, Luther A. Bartelt, MD, David van Duin, MD, PhD, and Anne M. \\ Lachiewicz, MD, MPH ${ }^{*}$ \\ Division of Infectious Diseases, University of North Carolina, CB 7030, 130 Mason Farm Road, \\ Chapel Hill, NC 27599, USA
}

\section{Keywords}

Solid organ transplant; Endemic mycoses; Histoplasmosis; Blastomycosis; Coccidioidomycosis

\section{INTRODUCTION}

The endemic mycoses are a group of thermally dimorphic fungal pathogens occupying a specific geographic range. This geographic restriction occurs as a result of the unique environmental requirements that best promote sporulation for each species. In North America, the chief endemic mycoses are histoplasmosis, coccidioidomycosis, and blastomycosis.

\section{GENERAL PRINCIPLES}

Although they can cause serious infections, all 3 endemic mycoses are surprisingly rare in solid organ transplant (SOT) recipients (Table 1). ${ }^{1,2}$ A prospective study performed in 15 transplant centers throughout the United States, including in high incidence areas, found only 33 cases of endemic mycoses among 16,806 patients who received a SOT during the 5year study period; 23 were histoplasmosis, 6 were coccidioidomycosis, and 4 were blastomycosis. ${ }^{1}$ By way of contrast, the incidence of invasive candidiasis in SOT recipients is approximately an order of magnitude higher. ${ }^{3}$ The incidence of the endemic mycoses is typically greatest in the 12 months after transplant, but the risk period extends for years thereafter. ${ }^{1,4-7}$

Histoplasmosis, coccidioidomycosis, and blastomycosis are all caused by environmental, soil-based fungi that are acquired chiefly, although not exclusively, through inhalation of conidia that have been aerosolized as a result of disturbance of the soil in which they are produced. ${ }^{8}$ The causative fungi are all thermally dimorphic, existing initially as a mold in the environment and then once in the body transforming themselves into either yeasts or, in the case of coccidioidomycosis, specialized structures called spherules. ${ }^{8,9}$ The fungi

\footnotetext{
*Corresponding author. anne_lachiewicz@med.unc.edu.

Disclosure Statement: D. van Duin has served as a consultant for Allergan, Achaogen, Shionogi, Tetraphase, Sanofi-Pasteur, Medimmune, and Astellas, and has received research funding from Steris Inc and Scynexis. A.M. Lachiewicz has served as a consultant for Destum Partners and KPB Biosciences, and received research funding from GlaxoSmithKline. J.S. Nel and L.A. Bartelt have no disclosures.
} 
typically establish themselves initially in the lung, although whether this is clinically apparent or not depends on a balance between the burden of disease and the state of the host immune system. Clinical disease can also occur when immunosuppression causes a loss of containment of a previously controlled infection, such as occurs from antirejection medication. ${ }^{10,11}$ Dissemination of the fungus can occur throughout the body if the immune system is unable to control the infection within the lungs. In the case of histoplasmosis and coccidioidomycosis, rare cases of disease acquired by an infected allograft have also been described; there are no reports of this with blastomycosis to date. ${ }^{1,12-15}$ There is typically a median of 2 weeks from symptoms onset until the diagnosis is ultimately made. ${ }^{5,7}$ In general, SOT recipients have been found to have more severe disease and a higher diseaserelated mortality from the endemic mycoses than immunocompetent patients. ${ }^{2-6}$

Currently, no single diagnostic test has optimal sensitivity and specificity to reliably diagnose any of the endemic mycoses. Thus, in situations where histoplasmosis, blastomycosis, or coccidioidomycosis are considered, multiple different tests should be used. In general, microscopy, culture, antigen detection, and antibody assays are wellestablished for all the endemic mycoses, although with important differences in their limitations that vary by species. Polymerase chain reaction testing is less well-established and often not commercially available, but offers the potential to complement the existing diagnostic armamentarium.

The agents used for treatment of the endemic mycoses are the polyenes (with liposomal amphotericin B now preferred) and the azoles (chiefly itraconazole or fluconazole). In general, mild infections can be treated with an azole alone, but more severe and/or disseminated disease (as occurs frequently in SOT recipients) requires initial therapy with amphotericin B and transition to an azole once clinical improvement occurs. ${ }^{16-18}$ Most SOT recipients with histoplasmosis, blastomycosis, and coccidioidomycosis generally require at least 12 months of treatment along with a temporary decrease in immunosuppressive regimens if possible. A risk of recrudescence or relapse exists for all of the endemic mycoses. However, the role and benefit of secondary prophylaxis is unclear and much debated.

\section{HISTOPLASMOSIS}

\section{Epidemiology}

Mycelial growth in histoplasmosis is favored in soil in climates with moderate temperatures (between $15^{\circ} \mathrm{C}$ and $40^{\circ} \mathrm{C}$ ), high relative humidity and a soil $\mathrm{pH}$ of greater than 5.5, although spores can survive for many years in less favorable environmental conditions. ${ }^{19}$ Bird and bat guano provides a high nitrogen, phosphorus, and organic matter content that is especially advantageous for histoplasmosis' sporulation, allowing for mycelial growth even in the absence of soil. ${ }^{20}$ Typical risk factors for histoplasmosis acquisition in endemic areas include spelunking, farming, cleaning up bird droppings, refurbishing buildings that have been inhabited by birds or bats, such as barns, or other activities that disturb the soil. ${ }^{19,21}$

In the United States, studies from the 1950s to the 1970s identified areas of endemicity on the basis of positive histoplasmin skin test reactivity. Within North America, these areas are 
centered around the Mississippi and Ohio River valleys (Fig. 1). Outside the United States, areas in Central and South America, and large parts of Africa and Australasia, are also considered endemic. ${ }^{21,22}$ However, it is likely that histoplasmosis can at least occasionally be acquired from a much wider range of environments than previously thought, especially in immunocompromised hosts. ${ }^{23,24}$

\section{Pathogenesis}

Infection with Histoplasma capsulatum is typically acquired when aerosolized micro-conidia are inhaled, because these infectious particles are small enough to reach the alveoli. ${ }^{10,21}$ Once in the lung, the microcondia transform into yeasts and are phagocytosed by macrophages, within which they initially proliferate and may be transported throughout the reticuloendothelial system. Approximately 1 to 2 weeks are required before sufficient Th1 cell-mediated immune response is generated to either kill or control the fungi in a quiescent state, driven by cytokines including interleukin-12, tumor necrosis factor- $\mathrm{a}$, and interferon$\gamma .{ }^{25}$ This process may be impaired in SOT recipients. In addition, previous immunologic control of the fungus can be lost in patients who later receive immunosuppressant medication. ${ }^{10}$

Histoplasmosis in SOT recipients can thus be acquired in 1 of 2 main ways: as a new (primary) infection or via reactivation of a previously controlled infection. A surprisingly low baseline incidence in endemic areas (usually $<0.5 \%$ ) combined with dramatic increases seen during community outbreaks argue that primary infection may be the dominant mode of acquisition. ${ }^{5,26-28}$ Rarely, histoplasmosis can also rarely be transmitted via an infected allograft, although only a handful of confirmed cases of this have been published to date. 12,13

\section{Clinical Presentation}

In hosts with intact immunity, histoplasmosis is usually confined to the lungs, with a diverse array of presentations, including acute and chronic pneumonias, isolated pulmonary nodules, fibrosing mediastinitis, and broncholithiasis. In SOT recipients, however, presentation is mostly that of progressive disseminated disease. ${ }^{5,6,28}$ As may be expected from the pathogenesis of histoplasmosis, pulmonary involvement is extremely common (>80\%, although this may be subclinical and detectable only on chest computed tomography scans), and thereafter the sites most likely to be involved are lymphoid-rich tissues: bone marrow, liver, spleen, and gastrointestinal tract. 5,28 Typical symptoms include fever, fatigue, nonproductive cough, and diarrhea, and typical signs include hepatomegaly, splenomegaly, lymphadenopathy, and sometimes oral ulcers. Central nervous system (CNS) disease $(<10 \%)$ and skin $(<5 \%)$ involvement seem to be relatively uncommon. Almost any site can ultimately be involved however; rare cases of histoplasmosis in SOT recipients are reported involving the adipose tissue and tonsils. ${ }^{5,29}$ Patients can also present with an undifferentiated sepsis picture.

\section{Diagnosis}

No single test is sufficiently sensitive to reliably diagnose histoplasmosis in SOT recipients, so a strategy using multiple diagnostic modalities simultaneously is recommended (Table 2). 
The single most sensitive test is a urine Histoplasma antigen test, which is positive in approximately $93 \%$ of cases when the newer generation assays are used. The test's sensitivity correlates positively with disease severity. ${ }^{6,30}$ However, the assay's specificity is limited by cross-reactions to antigens from Blastomyces, Paracoccidioides, and Penicillium species. ${ }^{30-32}$ Blood, bone marrow, and bronchoalveolar lavage cultures are all moderately sensitive in disseminated disease, but typically take several weeks to become positive. ${ }^{33} \mathrm{~A}$ bronchoscopic lung biopsy or cytology is positive in approximately three-quarters of cases. ${ }^{6}$ Histoplasma capsulatum's distinctive histologic appearance is that of a yeast, 2 to $5 \mu \mathrm{m}$ in size, with narrow-based budding, often clustered within macrophages. ${ }^{34}$ The least sensitive test seems to be serum antibodies, with an overall sensitivity in SOT recipients of just 36\% in 1 large series. ${ }^{6}$ Of note, false-positive Aspergillus galactomannan results have been reported in SOT recipients who had histoplasmosis. ${ }^{35}$ This finding should be borne in mind in SOT patients from histoplasmosis-endemic areas.

\section{Treatment}

Even without clear evidence of dissemination, SOT recipients with histoplasmosis should generally be treated as if they have disseminated disease. ${ }^{21}$ Liposomal amphotericin B is preferred over both itraconazole and amphotericin B deoxycholate for initial treatment in moderate and severe cases of disseminated disease. ${ }^{16,36,37}$ Liposomal amphotericin $\mathrm{B}$ has a lower rate of associated toxicities than the deoxycholate form, and is also possibly more potent in disseminated histoplasmosis. ${ }^{36}$ Liposomal amphotericin B should even be considered in cases complicated by renal disease despite the potential for additional nephrotoxicity; in many cases, as the disease comes under control, renal function improves rather than worsens. ${ }^{21}$ Liposomal amphotericin B is generally given for 1 to 2 weeks, followed by oral itraconazole for at least a year (Table 3). All azoles have some activity in histoplasmosis, although posaconazole is possibly the best alternative to itraconazole in cases of drug intolerance or clinical failure. ${ }^{21}$ Rising minimum inhibitory concentrations to both fluconazole and voriconazole have been observed while on therapy (whereas this has not been demonstrated with posaconazole), and there is limited clinical experience with isavuconazole. ${ }^{38}$ There is no role for echinocandin therapy in histoplasmosis. ${ }^{31}$

Once the diagnosis of histoplasmosis is made, immunosuppressive medication should be reduced, although the optimal timing and strategy in this regard is unknown. Azole treatment can probably be stopped after 12 months if there is no evidence of active infection. Ideally, the urine and blood antigen tests should be negative by that point, although they may remain positive at a low level for years after clinical resolution of disease. Therapy should not be prolonged merely because of this low-level antigenemia. After completion of treatment, long-term suppressive azole therapy in SOT recipients may be considered, but there is little evidence to endorse this practice, and the risk of disease relapse after completion of therapy is less than 5\% when adequate initial therapy is given. ${ }^{6}$ In addition, in high-risk patients (eg, patients in whom no significant reduction of immunosuppression was possible), relapses can be screened for by serial urine antigen testing. ${ }^{16}$ Thus, chronic suppressive therapy may be unnecessary for the majority of SOT recipients. 


\section{Prognosis}

The mortality from histoplasmosis acquired after SOT is approximately $10 \% .^{1,6,28}$ In the largest study, $72 \%$ of the deaths occurred within 1 month after diagnosis, and on multivariate analysis those who died from histoplasmosis were statistically more likely to be older and to have had severe disease, as might be expected. ${ }^{6}$

\section{BLASTOMYCOSIS}

\section{Epidemiology}

A recent phylogenetic analysis has revealed that Blastomyces dermatitidis, the sole cause of blastomycosis, is in fact 2 distinct species, $B$ dermatitidis and Blastomyces gilchristii. ${ }^{39}$ The natural habitat of Blastomyces is largely unknown, partly because, unlike other dimorphic fungi, it is extremely difficult to culture the organism from soil samples. Interesting new phylogeographic work has found a strong association of blastomycosis with freshwater basins, which complements earlier findings that suggested that Blastomyces conidiophores required exposure to water before their conidia could be dispersed by air currents. ${ }^{40,41}$ In North America, endemic regions seem to be the US and Canadian areas bordering the Mississippi, Ohio, Tennessee, and Nelson River drainage basins, and a small area in the northeast surrounding the St Lawrence River (see Fig. 1). A detailed history usually reveals occupational or recreational activities that have disrupted the soil in these regions, such as construction, boating, fishing, cutting trees, or clearing brush. As with all endemic mycoses, however, cases can occasionally be seen outside these endemic regions (see Table 1). ${ }^{42}$

\section{Pathogenesis}

In a similar manner to other endemic fungi, Blastomyces conidia must generally be inhaled to acquire the infection. Once inside the lung, the conidia transform into the yeast phase, and can survive within macrophages. Both innate and cell-mediated immunity play vital roles in controlling blastomycosis, whereas the humoral immune system plays no clear role. ${ }^{43}$ Unlike histoplasmosis and coccidiomycosis, no cases of blastomycosis acquired via infected allograft have been reported. ${ }^{1}$

\section{Clinical Presentation}

In immunocompetent individuals, approximately one-half of blastomycosis infections are asymptomatic and, of the symptomatic cases, pulmonary infection occurs in approximately $80 \%$ and disseminated disease occurs in $25 \%$ to $40 \%$ - a far higher rate than seen with other endemic mycoses. ${ }^{17,44}$ Interestingly, from the limited number of cases published to date, the chief difference in presentation among SOT recipients is not necessarily a greater propensity for disseminated disease, but rather more severe pulmonary disease, with a higher consequent mortality. ${ }^{2,3,7}$ Lung involvement in SOT recipients more frequently progresses to acute respiratory distress syndrome and respiratory failure. In disseminated cases, the same typical sites are involved as with immunocompetent individuals. The skin is the most frequently involved extrapulmonary site, although multiple pustules or ulcers are more common than the classic verrucous lesions seen in immunocompetent patients. ${ }^{45,46}$ Bone 
(lytic lesions), genitourinary (prostatitis or epididymitis), and CNS (meningitis or abscess) involvement are the next most common manifestations.

\section{Diagnosis}

Blastomycosis has a distinctive appearance on histologic specimens, namely that of a large yeast, 8 to $15 \mu \mathrm{m}$ in size, with broad-based budding and a thick refractile cell wall. ${ }^{34}$ This characteristic appearance permits a rapid diagnosis to be provisionally made directly from sputum, bronchoalveolar lavage specimens, and tissue biopsies. This property is especially useful considering the frequent involvement of the skin, which provides an easily accessible biopsy site. A definitive diagnosis requires culturing the organism, but like the other endemic fungi this usually takes 1 to 4 weeks. Blastomycosis antigen enzyme-linked immunoassay tests can be performed on urine, blood, and cerebrospinal fluid samples, with urine having the greatest sensitivity $(76 \%-93 \%) .{ }^{47,48}$ Like the urine histoplasmosis antigen test, this also suffers from a lack of specificity, principally owing to cross-reaction with other endemic fungi. ${ }^{43,47}$ Unlike histoplasmosis and coccidiomycosis, commercially available serologic testing in blastomycosis has poor sensitivity and therefore little clinical usefulness. 49

\section{Treatment}

In immunocompetent patients, milder non-CNS forms of blastomycosis may be treated entirely with an azole, typically itraconazole. However, because of the greater propensity for severe disease, it is recommended that blastomycosis cases in SOT recipients generally be treated with amphotericin B for 1 to 2 weeks initially, or until improvement is noted. ${ }^{17,43}$ Thereafter, as with histoplasmosis, approximately 12 months of oral itraconazole should be given. Itraconazole is probably more efficacious than fluconazole, and considerably more clinical experience exists with itraconazole than with any other of the azoles in the treatment of blastomycosis (see Table 3)..$^{50}$

\section{Prognosis}

The limited numbers of cases of blastomycosis in SOT recipients reported in the literature makes assessing outcomes with any precision difficult, but mortality in SOT recipients with blastomycosis seems to be in the $35 \%$ to $38 \%$ range (although the rate directly attributable to blastomycosis itself is likely closer to $25 \%)^{2,7}$ This mortality rate is higher than that seen in immunocompetent patients, though lower than seen in patients with malignancies or AIDS. ${ }^{7}$

\section{COCCIDIODOMYCOSIS}

\section{Epidemiology}

Coccidiodomycosis is caused by 1 of 2 species: Coccidioides immitis or Coccidioides posadasii. ${ }^{51}$ Unlike Histoplasma and Blastomyces, Coccidioides is found exclusively within in hot, dry climates, in arid and semiarid soil..$^{52}$ Specifically, Coccidioides is found in the southwestern United States, in the San Joaquin Valley, southern California, Texas, Arizona, and New Mexico, together with northern Mexico and noncontiguous areas in South America (see Fig. 1). ${ }^{53,54}$ C immitis is found predominantly within California and $C$ posadasii is found in the remainder of the endemic areas in the Western hemisphere. Drought conditions 
are associated with a higher incidence of reported coccidioidomycosis the following year, possibly because Coccidioides is relatively more tolerant of such conditions than competing organisms, and because dry conditions favor spore distribution. ${ }^{54}$ In endemic areas, sandstorms, military exercises, and outdoor construction work are recognized risk factors for disease acquisition. ${ }^{55}$

\section{Pathogenesis}

Maturing mycelial cells develop within the soil into arthroconidia, which are prone to be aerosolized by air currents or other disruptions of the soil. When inhaled, the arthroconidia form unique structures called spherules. Each of these develops to contain viable spores that can form further spherules when the original spherule ruptures, thereby quickly generating an exponential increase in fungal burden if unchecked. T-cell immunity is the principal form of control required for coccidioidomycosis, which may otherwise spread to extrapulmonary locations. Disseminated coccidioidomycosis is associated with a failure to generate an interferon- $\gamma$-led delayed-type hyper-sensitivity response to coccidioidal antigens. ${ }^{56}$ In a similar manner to histoplasmosis and blastomycosis, coccidioidomycosis can either be acquired de novo or be reactivate from a dormant state if the patient loses prior immunologic control of the organism owing to immunosuppression. ${ }^{11}$ Rarely, coccidioidomycosis can be transmitted via infected allograft. ${ }^{14,15}$

\section{Clinical Manifestations}

In immunocompetent hosts, approximately $60 \%$ of disease is asymptomatic and the vast majority of the remainder manifests as isolated pulmonary disease, with only less than $0.5 \%$ of patients having disseminated infection. ${ }^{55}$ In immunocompromised hosts, such as SOT recipients, the rates of disease dissemination increase markedly, causing an increase in mortality and morbidity. Pulmonary disease mimics community-acquired pneumonia and can range from minimally symptomatic to fulminant disease. Apart from the lung, common sites for dissemination are the CNS, liver, spleen, kidney, skin, and joints. ${ }^{4,57}$

\section{Diagnosis}

The spherule is pathognomonic for coccidioidomycosis, and thus identification of it from any sample establishes the diagnosis. Coccidioides cultures readily on most media in approximately 1 week. ${ }^{4}$ Laboratory personnel should be warned that coccidioidomycosis is suspected, because biocontainment procedures are required for safety when working with cultures. In tissue samples, spherules may be surrounded by either a granulomatous or a suppurative inflammatory response. ${ }^{4}$ The sensitivity of serologic tests is lessened in SOT recipients, who may not mount as robust an antibody response. ${ }^{4,58}$ Furthermore, a detectable serologic response may take 3 or more weeks to develop, causing false-negative results in early infection. However, because antibody levels generally decrease to undetectable levels with successful clearance of infection, a positive result typically represents either recent or active infection. ${ }^{59}$ Overall, enzyme-linked immunoassays are more sensitive but less specific than immunodiffusion tests; thus, the immunodiffusion tests are often used as confirmation tests for positive enzyme-linked immunoassay results. Urine or serum antigen testing is insensitive but most likely to be positive in disseminated disease. Cross-reaction with Histoplasma antigen test occurs. ${ }^{60,61}$ 


\section{Treatment}

As with the treatment of other endemic fungi in SOT recipients, mild pulmonary forms of the disease can be treated with azoles alone, but severe or disseminated cases generally require intravenous amphotericin B therapy initially, followed by azole therapy for approximately 12 months (see Table 3). Fluconazole and itraconazole are the most commonly used azoles, with fluconazole generally being preferred on the basis of more reliable absorption and less severe drug-drug interactions. A randomized, controlled trial comparing the 2 azoles failed to find a statistically significant difference in clinical response or relapse rate between them, although there was a trend toward itraconazole superiority. ${ }^{62}$

Fluconazole is the recommended first-line treatment for CNS infections, in contrast with histoplasmosis and blastomycosis, where the initial treatment for infections involving the CNS should be with amphotericin B. Immunosuppression should be lessened when possible, at least until the infection has begun to improve. ${ }^{59}$ The risk of recrudescent infection in SOT recipients with evidence of prior coccidioidomycosis may be substantial, and is far higher than seen with the other endemic mycoses. ${ }^{4,57,59}$ Thus, patients with a history of coccidioidomycosis should receive preemptive therapy after transplantation. Many experts also tend to preemptively treat all SOT recipients in endemic areas, regardless of the evidence for prior coccidioidomycosis. ${ }^{59}$ In either case, the usual duration of therapy is 6 to 12 months. Furthermore, after successful treatment of SOT recipients, indefinite secondary prophylaxis with fluconazole is often necessary for as long as the patient takes immunosuppressive medications, because the rate of relapse is otherwise unacceptably high.

\section{Prognosis}

Although heterogeneous, the mortality rate in SOT recipients who develop coccidioidomycosis is substantial, and higher than seen with the other endemic mycosis. Early reports from the 1980s showed mortality rates of up to $62 \%$, and a large-scale study 2 decades later highlighted a $43 \%$ mortality attributable to coccidioidomycosis. ${ }^{1,4}$ Mortality rates are higher with disseminated disease than localized pulmonary disease.

\section{TREATMENT ISSUES IN SOLID ORGAN TRANSPLANT RECIPIENTS}

The primary agents available to treat the endemic mycoses are amphotericin B and the triazole antifungals. The echinocandins have poor in vitro activity against the dimorphic fungi and should not be considered as treatment options for them. ${ }^{16,17,59,63}$ Amphotericin B is only available intravenously, in either a deoxycholate or a liposomal form. When the drug is required, the liposomal formulation is preferred owing to its lower toxicity, particularly nephrotoxicity. In a randomized controlled trial of disseminated histoplasmosis in patients with AIDS, there was also a trend toward a higher clinical success rate and a lower mortality rate with the liposomal amphotericinB. ${ }^{36}$ Common side effects include nephrotoxicity, hypokalemia, and hypomagnesemia, as well as infusion-related chills. Severe disease from the endemic mycoses is often accompanied by a degree of renal impairment, but renal dysfunction should not necessarily dissuade clinicians from using amphotericin $\mathrm{B}$, because it is preferred over the azoles in most cases of severe disease. ${ }^{16-18,21}$ Although the CNS penetration of amphotericin B is poor $(<3 \%)$, amphotericin B has demonstrable efficacy and 
is recommended first-line therapy for meningitis in both histoplasmosis and blastomycosis, although not coccidioidomycosis. ${ }^{16-18}$

Of the triazoles, the bulk of clinical experience lies with the first-generation agents, itraconazole and fluconazole. Voriconazole, posaconazole, and isavuconazole are less wellstudied despite their demonstrable in vitro activity, and their clinical evidence base primarily consists of small case series, often as salvage therapy, and with varying degrees of success. 28,64-67 Fluconazole has oral bioavailability of more than $90 \%$, and absorption is not significantly affected by food or gastric acidity. ${ }^{68}$ The reliability of its absorption precludes the need to check plasma levels routinely. Fluconazole has the best CNS penetration of any of the available antifungal drugs (approximately 75\%) and is used as an agent of first choice for coccidioidomycosis meningitis. ${ }^{18,69}$

Itraconazole is available both as a capsule or a solution. The solution formulation is preferred because of greater bioavailability, although gastrointestinal tolerability can be more problematic. Importantly, instructions to maximize bioavailability are opposite depending on the formulation. Food and an acidic gastric $\mathrm{pH}$ improve absorption of the capsule form of the drug (and so proton pump inhibitors, $\mathrm{H}_{2}$-antagonists, and antacids are contraindicated, whereas acidic cola beverages can improve absorption) ${ }^{70,71}$ By contrast, the oral solution is best absorbed on an empty stomach, and gastric $\mathrm{pH}$ has no effect. ${ }^{72}$ The erratic absorption of either form of the drug makes checking blood levels mandatory. ${ }^{73} \mathrm{~A}$ further important limitation of itraconazole is its poor CNS penetration, although successful treatment of meningitis is nonetheless achievable. ${ }^{69}$ Despite these disadvantages, itraconazole seems to be more efficacious than fluconazole in histoplasmosis and possibly in blastomycosis as well, accounting for its preference as the azole of choice for these conditions. ${ }^{50,74}$

Drug-drug interactions between commonly used immunosuppressive medications in SOT recipients and the antifungal medications discussed are essentially limited to the triazole class. These agents all target the fungal cytochrome P450-dependent enzyme lanosterol 14a-demethylase, thereby inhibiting fungal ergosterol production. ${ }^{75}$ However, all the azoles have varying degrees of affinity for various human cytochrome P450 enzyme system isoforms as well, and this property accounts for the bulk of the drug-drug interactions witnessed. ${ }^{76}$ In general, fluconazole has the least potent inhibition of cytochrome P450, and thus the fewest drug-drug interactions. The other mechanism of drug-drug interactions is via P-glycoprotein, an efflux pump for xenobiotics, which the triazoles similarly can inhibit and/or be a substrate of. ${ }^{76,77}$

It takes approximately 1 week after starting a triazole antifungal for the full effect of the enzyme inhibition to be felt. Conversely, when the triazole therapy is discontinued, the enzyme inhibition can last for up to a month thereafter. ${ }^{76}$ Close attention to azoles and immunosuppressive drug levels and dosage adjustments should be taken, particularly around these times. The effects of the antifungal drugs on commonly used immunosuppressive medications are summarized in Table 4. In general, drug levels of the calcineurin inhibitors (eg, tacrolimus) and mammalian target of rapamycin inhibitors (eg, sirolimus) almost always require dose reduction when triazoles are used. Of the listed antifungals, only isavuconazole 
has been documented to alter mycophenolate levels. The data for increased prednisone exposure with azoles that are strong CYP3A4 inhibitors (itraconazole, voriconazole, posaconazole, and ketoconazole) are contradictory, and so monitoring for steroid side effects is recommended. ${ }^{78-81}$ There is no evidence of significant drug-drug interactions with prednisone and any of the other antifungals.

Reductions in immunosuppressive drug exposure can cause an immune reconstitution syndrome (IRS) with any of the endemic fungi. This syndrome is manifest by an immunologically mediated worsening of the symptoms and signs of the infection, and may be hard to distinguish from treatment failure. ${ }^{82}$ Clues to IRS include clinical deterioration despite adequate antifungal therapy, a failure to culture viable organisms from involved body sites, and stable or decreasing antigen levels for the endemic mycoses despite the clinical worsening. ${ }^{83}$ Management is on a case-by-case basis, and depends on delicately navigating the trade-off between the need to control the infection and to maintain an adequate level of immunosuppression to prevent organ rejection. Mild cases of IRS usually settle without intensifying immunosuppression, but IRS reactions can be life threatening, especially if they occur in sites such as the CNS, and these more severe instances usually mandate temporarily increasing the level of immunosuppression again.

\section{PROPHYLAXIS REGIMENS IN SOLID ORGAN TRANSPLANT RECIPIENTS: AN UNRESOLVED ISSUE}

A donor known with active disease with any of the endemic fungi is not considered a suitable candidate until (in the case of living donors) several months of therapy have controlled the infection. ${ }^{84}$ Nonetheless, active donor infection is sometimes only discovered after transplantation has occurred, in which case primary prophylaxis of the recipient is indicated (Table 5). The other definite indication for peritransplant prophylaxis is in SOT recipients with evidence of prior coccidioidomycosis. This evidence may include positive serologic tests or thin-walled cavities seen on chest radiographs or computed tomography scans. Equivocal cases required specialist assessment, although many experts give prophylaxis to all SOT recipients if they reside in a coccidioidomycosis-endemic area, regardless of prior coccidioidomycosis or not. ${ }^{59}$ There is only limited evidence for this practice, however. Primary prophylaxis in patients living in areas endemic for histoplasmosis or blastomycosis, and secondary prophylaxis in patients with a history of prior histoplasmosis or blastomycosis is probably unnecessary. This probably includes patients living in endemic areas who have computed tomography evidence of calcified granulomas in lungs, liver, spleen, lymph nodes, or other organs, because the risk of reinfection in this case seems low to nonexistent. ${ }^{16,26,85}$

There is a similar lack of definitive evidence to guide secondary prophylaxis in SOT recipients after completion of a treatment course. The relapse rate after treatment completion in coccidioidomycosis is particularly high in SOT recipients, and so consensus opinion is that all such patients should receive life-long secondary prophylaxis. ${ }^{59}$ The role of secondary prophylaxis for histoplasmosis and blastomycosis is less clear, and should 
probably be limited to cases at high risk of relapse only (see Table 5). ${ }^{16,84}$ These high-risk scenarios would include patients in whom immunosuppression was not able to be lessened.

\section{SUMMARY}

Histoplasmosis, blastomycosis, and coccidioidomycosis are all relatively rare in SOT recipients, even those from endemic areas. However, they are more difficult to diagnose than many other infections that plague this population and can cause significant morbidity and mortality if they are not identified early. Therapy for the endemic mycoses is typically given for at least a year and is frequently complicated by drug-drug interactions between the triazoles and antirejection medications that requires close monitoring of immunosuppressive drug levels both when the triazoles are started and when they are stopped again after treatment completion.

\section{Acknowledgments}

Funding: This work is supported in part by the National Center for Advancing Translational Sciences, National Institutes of Health Grant KL2TR001109 (A.M. Lachiewicz) and National Institutes of Health National Institutes of Health National Institute of Allergy and Infectious Diseases Grant K08-AI108730 (L.A. Bartelt).

\section{REFERENCES}

1. Kauffman CA, Freifeld AG, Andes DR, et al. Endemic fungal infections in solid organ and hematopoietic cell transplant recipients enrolled in the Transplant-Associated Infection Surveillance Network (TRANSNET). Transpl Infect Dis 2014;16(2):213-24. [PubMed: 24589027]

2. Grim SA, Proia L, Miller R, et al. A multicenter study of histoplasmosis and blastomycosis after solid organ transplantation. Transpl Infect Dis 2012;14(1):17-23. [PubMed: 21749587]

3. Pappas PG, Alexander BD, Andes DR, et al. Invasive fungal infections among organ transplant recipients: results of the Transplant-Associated Infection Surveillance Network (TRANSNET). Clin Infect Dis 2010;50(8):1101-11. [PubMed: 20218876]

4. Blair JE, Logan JL. Coccidioidomycosis in solid organ transplantation. Clin Infect Dis 2001;33(9): 1536-44. [PubMed: 11588699]

5. Cuellar-Rodriguez J, Avery RK, Lard M, et al. Histoplasmosis in solid organ transplant recipients: 10 years of experience at a large transplant center in an endemic area. Clin Infect Dis 2009;49(5): 710-6. [PubMed: 19635026]

6. Assi M, Martin S, Wheat LJ, et al. Histoplasmosis after solid organ transplant. Clin Infect Dis 2013;57(11):1542-9. [PubMed: 24046304]

7. Gauthier GM, Safdar N, Klein BS, et al. Blastomycosis in solid organ transplant recipients. Transpl Infect Dis 2007;9(4):310-7. [PubMed: 17428278]

8. Kauffman CA. Endemic mycoses: blastomycosis, histoplasmosis, and sporotrichosis. Infect Dis Clin North Am 2006;20(3):645-62, vii. [PubMed: 16984873]

9. Malcolm TR, Chin-Hong PV. Endemic mycoses in immunocompromised hosts. Curr Infect Dis Rep 2013; 15(6):536-43. [PubMed: 24197921]

10. Woods JP. Revisiting old friends: developments in understanding Histoplasma capsulatum pathogenesis. J Microbiol 2016; 54(3):265-76. [PubMed: 26920886]

11. Benedict K, Thompson GR, 3rd, Deresinski S, et al. Mycotic infections acquired outside areas of known endemicity, United States. Emerg Infect Dis 2015; 21(11):1935-41. [PubMed: 26485441]

12. Limaye AP, Connolly PA, Sagar M, et al. Transmission of Histoplasma capsulatum by organ transplantation. N Engl J Med 2000; 343(16):1163-6. [PubMed: 11036122]

13. Schwenk HT, Vo P, Moffitt K, et al. Allograft-transmitted Histoplasma capsulatum infection in a solid organ transplant recipient. J Pediatric Infect Dis Soc 2013; 2(3):270-3. [PubMed: 26619482] 
14. Dierberg KL, Marr KA, Subramanian A, et al. Donor-derived organ transplant transmission of coccidioidomycosis. Transpl Infect Dis 2012;14(3):300-4. [PubMed: 22176496]

15. Nelson JK, Giraldeau G, Montoya JG, et al. Donor-derived Coccidioides immitis endocarditis and disseminated infection in the setting of solid organ transplantation. Open Forum Infect Dis 2016;3(3):ofw086. [PubMed: 27413765]

16. Wheat LJ, Freifeld AG, Kleiman MB, et al. Clinical practice guidelines for the management of patients with histoplasmosis: 2007 update by the Infectious Diseases Society of America. Clin Infect Dis 2007;45(7):807-25. [PubMed: 17806045]

17. Chapman SW, Dismukes WE, Proia LA, et al. Clinical practice guidelines for the management of blastomycosis: 2008 update by the Infectious Diseases Society of America. Clin Infect Dis 2008;46(12):1801-12. [PubMed: 18462107]

18. Galgiani JN, Ampel NM, Blair JE, et al. Executive summary: 2016 Infectious Diseases Society of America (IDSA) clinical practice guideline for the treatment of coccidioidomycosis. Clin Infect Dis 2016;63(6):717-22. [PubMed: 27559032]

19. Mott DF. The opposite end of the spectrum-managing nongame species that are prospering In: Proceedings of the Workshop on Management of Nongame Species and Ecological Communities. Kensington (KY), 6 11-12, 1985p. 151-8.

20. Krzysik AJ. Birds in human modified environments and bird damage control: social, economic, and health implications. Washington, DC: US Construction Engineering Research Laboratory; 1989.

21. Wheat LJ, Azar MM, Bahr NC, et al. Histoplasmosis. Infect Dis Clin North Am 2016;30(1):20727. [PubMed: 26897068]

22. Kauffman CA. Histoplasmosis. Clin Chest Med 2009;30(2):217-25, v. [PubMed: 19375629]

23. Bahr NC, Antinori S, Wheat LJ, et al. Histoplasmosis infections worldwide: thinking outside of the Ohio River valley. Curr Trop Med Rep 2015;2(2):70-80. [PubMed: 26279969]

24. Centers for Disease Control and Prevention. Histoplasmosis in a state where it is not known to be endemic-Montana, 2012-2013. MMWR Morb Mortal Wkly Rep 2013;62(42):834-7. [PubMed: 24153314]

25. Horwath MC, Fecher RA, Deepe GS, Jr. Histoplasma capsulatum, lung infection and immunity. Future Microbiol 2015;10(6):967-75. [PubMed: 26059620]

26. Vail GM, Young RS, Wheat LJ, et al. Incidence of histoplasmosis following allogeneic bone marrow transplant or solid organ transplant in a hyperendemic area. Transpl Infect Dis 2002;4(3): 148-51. [PubMed: 12421460]

27. Wheat LJ, Smith EJ, Sathapatayavongs B, et al. Histoplasmosis in renal allograft recipients. Two large urban outbreaks. Arch Intern Med 1983;143(4):703-7. [PubMed: 6301394]

28. Freifeld AG, Iwen PC, Lesiak BL, et al. Histoplasmosis in solid organ transplant recipients at a large Midwestern university transplant center. Transpl Infect Dis 2005;7(3-4):109-15. [PubMed: 16390398]

29. Dufresne SF, LeBlanc RE, Zhang SX, et al. Histoplasmosis and subcutaneous nodules in a kidney transplant recipient: erythema nodosum versus fungal panniculitis. Transpl Infect Dis 2013;15(2):E58-63. [PubMed: 23331504]

30. Hage CA, Ribes JA, Wengenack NL, et al. A multicenter evaluation of tests for diagnosis of histoplasmosis. Clin Infect Dis 2011;53(5):448-54. [PubMed: 21810734]

31. Kauffman CA. Histoplasmosis: a clinical and laboratory update. Clin Microbiol Rev 2007;20(1): 115-32. [PubMed: 17223625]

32. Wheat J, Wheat H, Connolly P, et al. Cross-reactivity in Histoplasma capsulatum variety capsulatum antigen assays of urine samples from patients with endemic mycoses. Clin Infect Dis 1997;24(6):1169-71. [PubMed: 9195077]

33. Assi MA, Sandid MS, Baddour LM, et al. Systemic histoplasmosis: a 15-year retrospective institutional review of 111 patients. Medicine (Baltimore) 2007; 86(3):162-9. [PubMed: 17505255]

34. Guarner J, Brandt ME. Histopathologic diagnosis of fungal infections in the 21 st century. Clin Microbiol Rev 2011;24(2):247-80. [PubMed: 21482725] 
35. Vergidis P, Walker RC, Kaul DR, et al. False-positive Aspergillus galactomannan assay in solid organ transplant recipients with histoplasmosis. Transpl Infect Dis 2012;14(2):213-7. [PubMed: 22093368]

36. Johnson PC, Wheat LJ, Cloud GA, et al. Safety and efficacy of liposomal amphotericin B compared with conventional amphotericin B for induction therapy of histoplasmosis in patients with AIDS. Ann Intern Med 2002;137(2):105-9. [PubMed: 12118965]

37. Wheat LJ, Cloud G, Johnson PC, et al. Clearance of fungal burden during treatment of disseminated histoplasmosis with liposomal amphotericin B versus itraconazole. Antimicrob Agents Chemother 2001;45(8):2354-7. [PubMed: 11451696]

38. Wheat LJ, Connolly P, Smedema M, et al. Activity of newer triazoles against Histoplasma capsulatum from patients with AIDS who failed fluconazole. J Antimicrob Chemother 2006;57(6): 1235-9. [PubMed: 16627592]

39. Brown EM, McTaggart LR, Zhang SX, et al. Phylogenetic analysis reveals a cryptic species Blastomyces gilchristii, sp. nov. within the human pathogenic fungus Blastomyces dermatitidis. PLoS One 2013;8(3):e59237. [PubMed: 23533607]

40. McDonough ES, Wisniewski TR, Penn LA, et al. Preliminary studies on conidial liberation of Blastomyces dermatitidis and Histoplasma capsulatum. Sabouraudia 1976;14(2):199-204. [PubMed: 959945]

41. McTaggart LR, Brown EM, Richardson SE. Phylogeographic analysis of Blastomyces dermatitidis and Blastomyces gilchristii reveals an association with North American Freshwater Drainage Basins. PLoS One 2016;11(7):e0159396. [PubMed: 27428521]

42. Baddley JW, Winthrop KL, Patkar NM, et al. Geographic distribution of endemic fungal infections among older persons, United States. Emerg Infect Dis 2011; 17(9):1664-9. [PubMed: 21888792]

43. McBride JA, Gauthier GM, Klein BS. Clinical manifestations and treatment of blastomycosis. Clin Chest Med 2017;38(3):435-49. [PubMed: 28797487]

44. Klein BS, Vergeront JM, Weeks RJ, et al. Isolation of Blastomyces dermatitidis in soil associated with a large outbreak of blastomycosis in Wisconsin. N Engl J Med 1986;314(9):529-34. [PubMed: 3945290]

45. Kauffman CA, Miceli MH. Histoplasmosis and blastomycosis in solid organ transplant recipients. J Fungi 2015;1(2):94-106.

46. Levy AL, Wilkin N, Poh-Fitzpatrick MB, et al. Verrucous nodules on the toes of a renal transplant recipient. Cutaneous blastomycosis. Arch Dermatol 2007; 143(5):653-8.

47. Durkin M, Witt J, Lemonte A, et al. Antigen assay with the potential to aid in diagnosis of blastomycosis. J Clin Microbiol 2004;42(10):4873-5. [PubMed: 15472368]

48. Frost HM, Novicki TJ. Blastomyces antigen detection for diagnosis and management of blastomycosis. J Clin Microbiol 2015;53(11):3660-2. [PubMed: 26338856]

49. Wheat LJ. Antigen detection, serology, and molecular diagnosis of invasive mycoses in the immunocompromised host. Transpl Infect Dis 2006;8(3):128-39. [PubMed: 16913971]

50. Pappas PG, Bradsher RW, Kauffman CA, et al. Treatment of blastomycosis with higher doses of fluconazole. The National Institute of Allergy and Infectious Diseases Mycoses Study Group. Clin Infect Dis 1997;25(2):200-5. [PubMed: 9332510]

51. Hector RF, Laniado-Laborin R. Coccidioidomycosis-a fungal disease of the Americas. PLoS Med 2005;2(1):e2. [PubMed: 15696207]

52. Fisher FS, Bultman MW, Johnson SM, et al. Coccidioides niches and habitat parameters in the southwestern United States: a matter of scale. Ann N Y Acad Sci 2007;1111:47-72. [PubMed: 17344527]

53. Lauer A, Talamantes J, Castanon Olivares LR, et al. Combining forces-the use of Landsat TM satellite imagery, soil parameter information, and multiplex PCR to detect Coccidioides immitis growth sites in Kern County, California. PLoS One 2014;9(11):e111921. [PubMed: 25380290]

54. Coopersmith EJ, Bell JE, Benedict K, et al. Relating coccidioidomycosis (valley fever) incidence to soil moisture conditions. Geohealth 2017;1:51-63. [PubMed: 29124249]

55. Hage CA, Knox KS, Wheat LJ. Endemic mycoses: overlooked causes of community acquired pneumonia. Respir Med 2012;106(6):769-76. [PubMed: 22386326] 
56. Ampel NM, Christian L. In vitro modulation of proliferation and cytokine production by human peripheral blood mononuclear cells from subjects with various forms of coccidioidomycosis. Infect Immun 1997;65(11):4483-7. [PubMed: 9353023]

57. Blair JE. Coccidioidomycosis in liver transplantation. Liver Transpl 2006;12(1):31-9. [PubMed: 16382459]

58. Blair JE, Coakley B, Santelli AC, et al. Serologic testing for symptomatic coccidioidomycosis in immunocompetent and immunosuppressed hosts. Mycopathologia 2006;162(5):317-24. [PubMed: 17123029]

59. Galgiani JN, Ampel NM, Blair JE, et al. 2016 Infectious Diseases Society of America (IDSA) clinical practice guideline for the treatment of coccidioidomycosis. Clin Infect Dis 2016;63(6):e112-46. [PubMed: 27470238]

60. Kuberski T, Myers R, Wheat LJ, et al. Diagnosis of coccidioidomycosis by antigen detection using cross-reaction with a Histoplasma antigen. Clin Infect Dis 2007;44(5):e50-4. [PubMed: 17278049]

61. Durkin M, Connolly P, Kuberski T, et al. Diagnosis of coccidioidomycosis with use of the Coccidioides antigen enzyme immunoassay. Clin Infect Dis 2008; 47(8):e69-73. [PubMed: 18781884]

62. Galgiani JN, Catanzaro A, Cloud GA, et al. Comparison of oral fluconazole and itraconazole for progressive, nonmeningeal coccidioidomycosis. A randomized, double-blind trial. Mycoses Study Group. Ann Intern Med 2000;133(9):676-86. [PubMed: 11074900]

63. Espinel-Ingroff A Comparison of In vitro activities of the new triazole SCH56592 and the echinocandins MK-0991 (L-743,872) and LY303366 against opportunistic filamentous and dimorphic fungi and yeasts. J Clin Microbiol 1998; 36(10):2950-6. [PubMed: 9738049]

64. Thompson GR, 3rd, Rendon A, Ribeiro Dos Santos R, et al. isavuconazole treatment of cryptococcosis and dimorphic mycoses. Clin Infect Dis 2016;63(3): 356-62. [PubMed: 27169478]

65. Catanzaro A, Cloud GA, Stevens DA, et al. Safety, tolerance, and efficacy of posaconazole therapy in patients with nonmeningeal disseminated or chronic pulmonary coccidioidomycosis. Clin Infect Dis 2007;45(5):562-8. [PubMed: 17682989]

66. Stevens DA, Rendon A, Gaona-Flores V, et al. Posaconazole therapy for chronic refractory coccidioidomycosis. Chest 2007;132(3):952-8. [PubMed: 17573510]

67. Restrepo A, Tobon A, Clark B, et al. Salvage treatment of histoplasmosis with posaconazole. J Infect 2007;54(4):319-27. [PubMed: 16824608]

68. Brammer KW, Farrow PR, Faulkner JK. Pharmacokinetics and tissue penetration of fluconazole in humans. Rev Infect Dis 1990;12(Suppl 3):S318-26. [PubMed: 2184510]

69. Kethireddy S, Andes D. CNS pharmacokinetics of antifungal agents. Expert Opin Drug Metab Toxicol 2007;3(4):573-81. [PubMed: 17696807]

70. Jaruratanasirikul S, Kleepkaew A. Influence of an acidic beverage (Coca-Cola) on the absorption of itraconazole. Eur J Clin Pharmacol 1997;52(3):235-7. [PubMed: 9218932]

71. Jaruratanasirikul S, Sriwiriyajan S. Effect of omeprazole on the pharmacokinetics of itraconazole. Eur J Clin Pharmacol 1998;54(2):159-61. [PubMed: 9626921]

72. Vyas KS, Bariola JR, Bradsher RW, Jr. Treatment of endemic mycoses. Expert Rev Respir Med 2010;4(1):85-95. [PubMed: 20387295]

73. Prentice AG, Glasmacher A. Making sense of itraconazole pharmacokinetics. J Antimicrob Chemother 2005;56(Suppl 1):i17-22. [PubMed: 16120630]

74. McKinsey DS, Kauffman CA, Pappas PG, et al. Fluconazole therapy for histoplasmosis. The National Institute of Allergy and Infectious Diseases Mycoses Study Group. Clin Infect Dis 1996;23(5):996-1001. [PubMed: 8922792]

75. Ghannoum MA, Rice LB. Antifungal agents: mode of action, mechanisms of resistance, and correlation of these mechanisms with bacterial resistance. Clin Microbiol Rev 1999;12(4):501-17. [PubMed: 10515900]

76. Dodds-Ashley E Management of drug and food interactions with azole anti-fungal agents in transplant recipients. Pharmacotherapy 2010;30(8):842-54. [PubMed: 20653361]

77. Lin JH, Yamazaki M. Role of P-glycoprotein in pharmacokinetics: clinical implications. Clin Pharmacokinet 2003;42(1):59-98. [PubMed: 12489979] 
78. Lebrun-Vignes B, Archer VC, Diquet B, et al. Effect of itraconazole on the pharmacokinetics of prednisolone and methylprednisolone and cortisol secretion in healthy subjects. Br J Clin Pharmacol 2001;51(5):443-50. [PubMed: 11422002]

79. Yamashita SK, Ludwig EA, Middleton E, Jr, et al. Lack of pharmacokinetic and pharmacodynamic interactions between ketoconazole and prednisolone. Clin Pharmacol Ther 1991;49(5):558-70. [PubMed: 1827622]

80. Varis T, Kivisto KT, Neuvonen PJ. The effect of itraconazole on the pharmacokinetics and pharmacodynamics of oral prednisolone. Eur J Clin Pharmacol 2000; 56(1):57-60. [PubMed: 10853878]

81. Zurcher RM, Frey BM, Frey FJ. Impact of ketoconazole on the metabolism of prednisolone. Clin Pharmacol Ther 1989;45(4):366-72. [PubMed: 2639662]

82. Gupta AO, Singh N. Immune reconstitution syndrome and fungal infections. Curr Opin Infect Dis 2011;24(6):527-33. [PubMed: 22025021]

83. Jazwinski A, Naggie S, Perfect J. Immune reconstitution syndrome in a patient with disseminated histoplasmosis and steroid taper: maintaining the perfect balance. Mycoses 2011;54(3):270-2. [PubMed: 19843232]

84. Singh N, Huprikar S, Burdette SD, et al. Donor-derived fungal infections in organ transplant recipients: guidelines of the American Society of Transplantation, infectious diseases community of practice. Am J Transplant 2012;12(9): 2414-28. [PubMed: 22694672]

85. Straub M, Schwarz J. The healed primary complex in histoplasmosis. Am J Clin Pathol 1955;25(7):727-41. [PubMed: 14387973]

86. Hage C, Kleiman MB, Wheat LJ. Histoplasmosis in solid organ transplant recipients. Clin Infect Dis 2010;50(1):122-3 [author reply: 123-4]. [PubMed: 20001525]

87. Manez R, Martin M, Raman D, et al. Fluconazole therapy in transplant recipients receiving FK506. Transplantation 1994;57(10):1521-3. [PubMed: 7515201]

88. Lumlertgul D, Noppakun K, Rojanasthien N, et al. Pharmacokinetic study of the combination of tacrolimus and fluconazole in renal transplant patients. J Med Assoc Thai 2006;89(Suppl 2):S738.

89. Canafax DM, Graves NM, Hilligoss DM, et al. Interaction between cyclosporine and fluconazole in renal allograft recipients. Transplantation 1991;51(5):1014-8. [PubMed: 2031258]

90. Mori T, Aisa Y, Kato J, et al. Drug interaction between oral solution itraconazole and calcineurin inhibitors in allogeneic hematopoietic stem cell transplantation recipients: an association with bioavailability of oral solution itraconazole. Int J Hematol 2009;90(1):103-7. [PubMed: 19472033]

91. Kramer MR, Marshall SE, Denning DW, et al. Cyclosporine and itraconazole interaction in heart and lung transplant recipients. Ann Intern Med 1990; 113(4):327-9. [PubMed: 2165371]

92. Kuypers DR, Claes K, Evenepoel P, et al. Drug interaction between itraconazole and sirolimus in a primary renal allograft recipient. Transplantation 2005;79(6):737. [PubMed: 15785385]

93. Sadaba B, Campanero MA, Quetglas EG, et al. Clinical relevance of sirolimus drug interactions in transplant patients. Transplant Proc 2004;36(10):3226-8. [PubMed: 15686733]

94. Mori T, Aisa Y, Kato J, et al. Drug interaction between voriconazole and calcineurin inhibitors in allogeneic hematopoietic stem cell transplant recipients. Bone Marrow Transplant 2009;44(6): 371-4. [PubMed: 19270729]

95. Venkataramanan R, Zang S, Gayowski T, et al. Voriconazole inhibition of the metabolism of tacrolimus in a liver transplant recipient and in human liver micro-somes. Antimicrob Agents Chemother 2002;46(9):3091-3. [PubMed: 12183280]

96. Romero AJ, Le Pogamp P, Nilsson LG, et al. Effect of voriconazole on the pharmacokinetics of cyclosporine in renal transplant patients. Clin Pharmacol Ther 2002;71(4):226-34. [PubMed: 11956505]

97. Lazowski J, Radzikowska B, Zadrozynska E. Determination of blood level of diphenylhydantoin in the treatment of epilepsy. The need for monitoring. Wiad Lek 1977;30(20):1613-6 [in Polish].

[PubMed: 930076] 
98. Sansone-Parsons A, Krishna G, Martinho M, et al. Effect of oral posaconazole on the pharmacokinetics of cyclosporine and tacrolimus. Pharmacotherapy 2007; 27(6):825-34. [PubMed: 17542765]

99. Berge M, Chevalier P, Benammar M, et al. Safe management of tacrolimus together with posaconazole in lung transplant patients with cystic fibrosis. Ther Drug Monit 2009;31(3):396-9. [PubMed: 19349930]

100. Merck \& Co. Inc. Noxafil@ (posaconazole) injection $18 \mathrm{mg} / \mathrm{mL}$ Noxafil@ (posaconazole) delayed-release tablets $100 \mathrm{mg}$ Noxafil® (posaconazole) oral suspension $40 \mathrm{mg} / \mathrm{mL}$. 2015.

101. Rivosecchi RM, Clancy CJ, Shields RK, et al. Effects of isavuconazole on the plasma concentrations of tacrolimus among solid-organ transplant patients. Antimicrob Agents Chemother 2017;61(9) [pii:e00970-17].

102. Groll AH, Desai A, Han D, et al. Pharmacokinetic assessment of drug-drug interactions of isavuconazole with the immunosuppressants cyclosporine, mycophenolic acid, prednisolone, sirolimus, and tacrolimus in healthy adults. Clin Pharmacol Drug Dev 2017;6(1):76-85.

[PubMed: 27273343] 


\section{KEY POINTS}

- $\quad$ Endemic mycoses are thermally dimorphic fungal pathogens occupying a specific geographic range.

- Histoplasmosis, coccidioidomycosis, and blastomycosis are the chief endemic mycoses in North America.

- Infections with endemic mycoses are uncommon, but can cause serious infection in solid organ transplant recipients. 


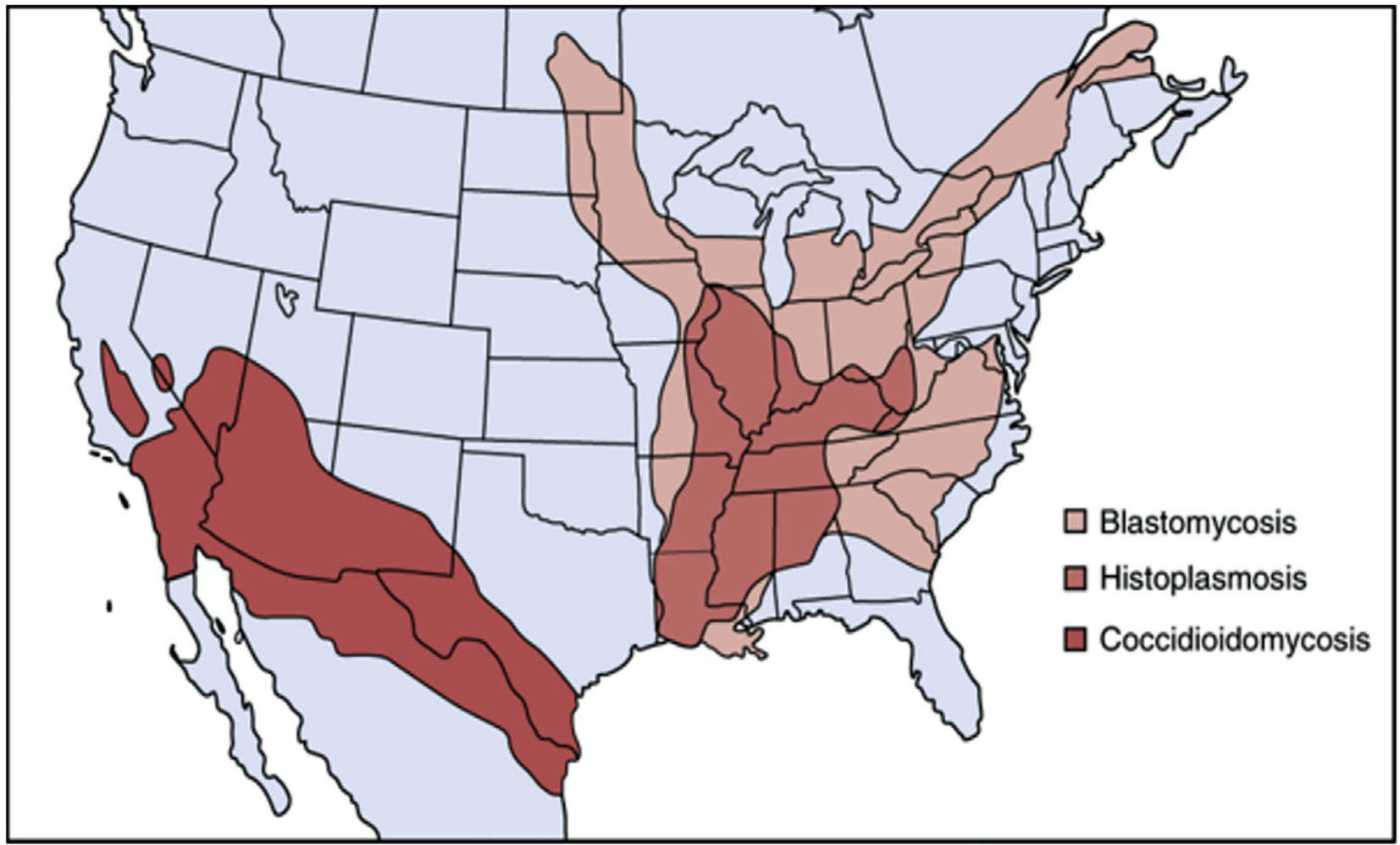

Fig. 1.

Geographic distribution of endemic fungal infections in the North America. (From Ryan KJ. The systemic fungal pathogens: cryptococcus, histoplasma, blastomyces, coccidioides, paracoccidioides. In: Ryan KJ, editor. Sherris medical microbiology. 7th edition. New York: McGraw-Hill; 2018. p. 750; with permission.) 


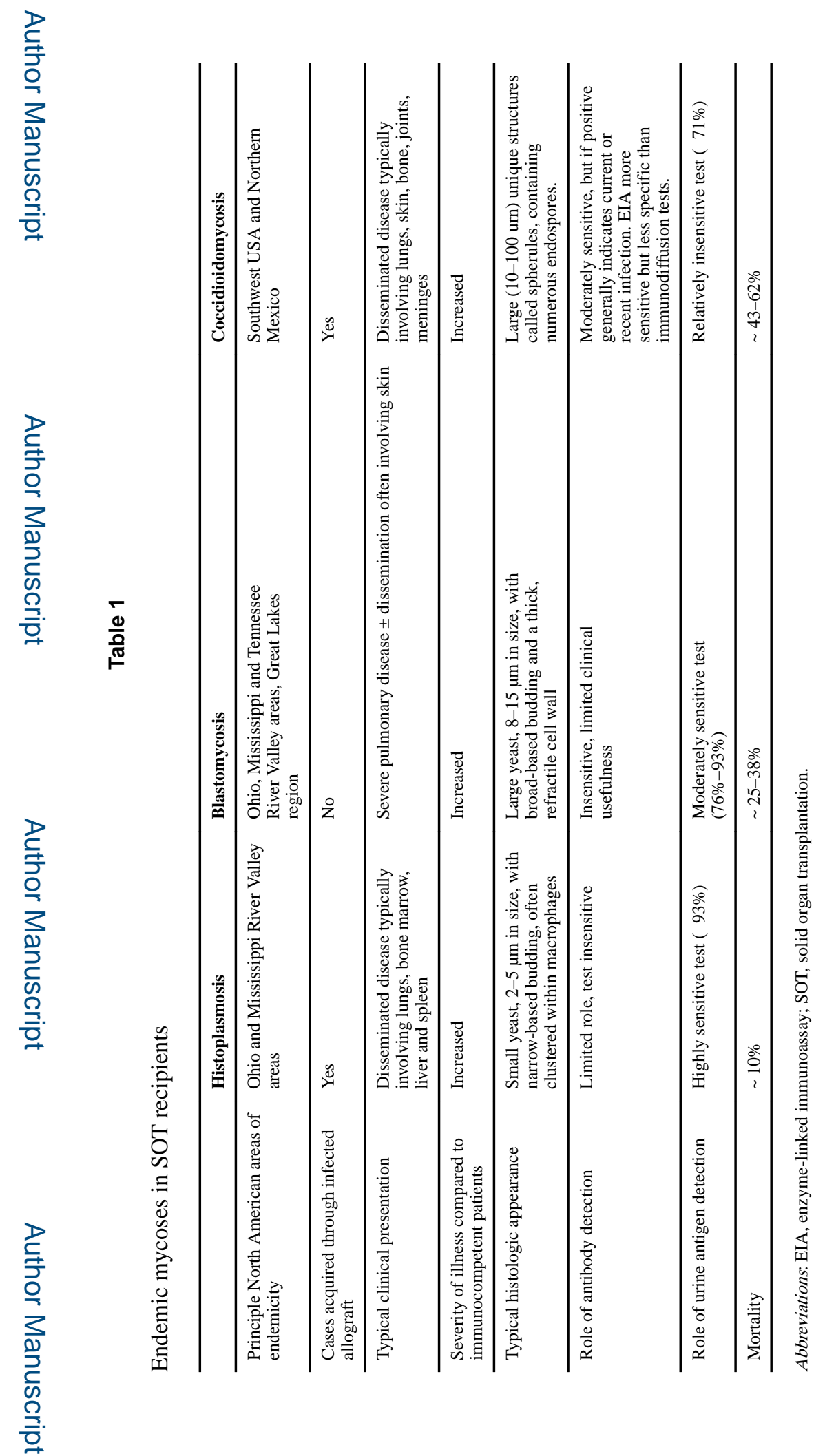

Infect Dis Clin North Am. Author manuscript; available in PMC 2019 September 01. 


\section{Table 2}

Approximate sensitivities of histoplasmosis diagnostic tests in solid-organ transplant recipients

\begin{tabular}{ll}
\hline Test & Approximate Sensitivity (\%) \\
\hline Urine antigen & 293 \\
Serum antigen & 80 \\
Antibody & 35 \\
Blood culture & $50-70$ \\
Bronchoalveolar lavage culture & $60-72$ \\
Lung biopsy or cytology & 77 \\
\hline
\end{tabular}

Data from Refs. $2,5,6,28,86$ 
Table 3

Typical therapeutic regimens for endemic fungi in SOT recipients

\begin{tabular}{|c|c|c|c|}
\hline & Mild Disease & Severe Disease & CNS Disease \\
\hline Histoplasmosis & $\begin{array}{l}\text { Itraconazole } 200 \mathrm{mg} \\
\text { every } 8 \text { hours for } 3 \mathrm{~d} \\
\text { and then twice daily } \\
\text { for } 12 \mathrm{mo}\end{array}$ & $\begin{array}{l}\text { Liposomal amphotericin } \\
\mathrm{B}(3 \mathrm{mg} / \mathrm{kg}) \text { for } 1-2 \mathrm{wk} \\
\text { then itraconazole } \\
200 \mathrm{mg} \text { twice daily for } \\
12 \mathrm{mo}\end{array}$ & $\begin{array}{l}\text { Liposomal amphotericin B } \\
(5 \mathrm{mg} / \mathrm{kg}) \text { for } \\
4-6 \mathrm{wk} \text { then } \\
\text { itraconazole } \\
200 \mathrm{mg} \text { twice } \\
\text { daily for } 12 \mathrm{mo}\end{array}$ \\
\hline Blastomycosis & $\begin{array}{l}\text { Itraconazole } 200 \mathrm{mg} \\
\text { every } 8 \text { hours for } 3 \mathrm{~d} \\
\text { and then twice daily } \\
\text { for } 12 \text { mo (but } \\
\text { consider treating as } \\
\text { for severe disease in } \\
\text { all } \\
\text { immunosuppressed } \\
\text { patients) }\end{array}$ & $\begin{array}{l}\text { Liposomal amphotericin } \\
\mathrm{B}(3 \mathrm{mg} / \mathrm{kg}) \text { for } 1-2 \mathrm{wk} \\
\text { then itraconazole } \\
200 \mathrm{mg} \text { twice daily for } \\
12 \mathrm{mo}\end{array}$ & $\begin{array}{l}\text { Liposomal amphotericin B } \\
(5 \mathrm{mg} / \mathrm{kg} \text { ) for } \\
4-6 \mathrm{wk} \text { then a } \\
\text { triazole for } 12 \mathrm{mo} \\
\text { (optimal triazole } \\
\text { unclear) }\end{array}$ \\
\hline Coccidioidomycosis & $\begin{array}{l}\text { Fluconazole } \\
400 \mathrm{mg} / \mathrm{d} \text { for at least } \\
12 \mathrm{mo}\end{array}$ & $\begin{array}{l}\text { Liposomal amphotericin } \\
\mathrm{B}(5 \mathrm{mg} / \mathrm{kg}) \text { for } 1-2 \mathrm{wk} \\
\text { then fluconazole } \\
400 \mathrm{mg} / \mathrm{d} \text { for at least } \\
12 \mathrm{mo}\end{array}$ & $\begin{array}{l}\text { Fluconazole } \\
400-1200 \mathrm{mg} / \mathrm{d}, \\
\text { continued } \\
\text { indefinitely }\end{array}$ \\
\hline
\end{tabular}

Abbreviations: CNS, central nervous system; SOT, solid organ transplantation. 


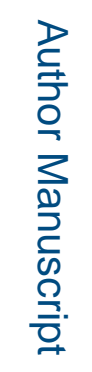

를

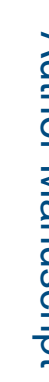

章

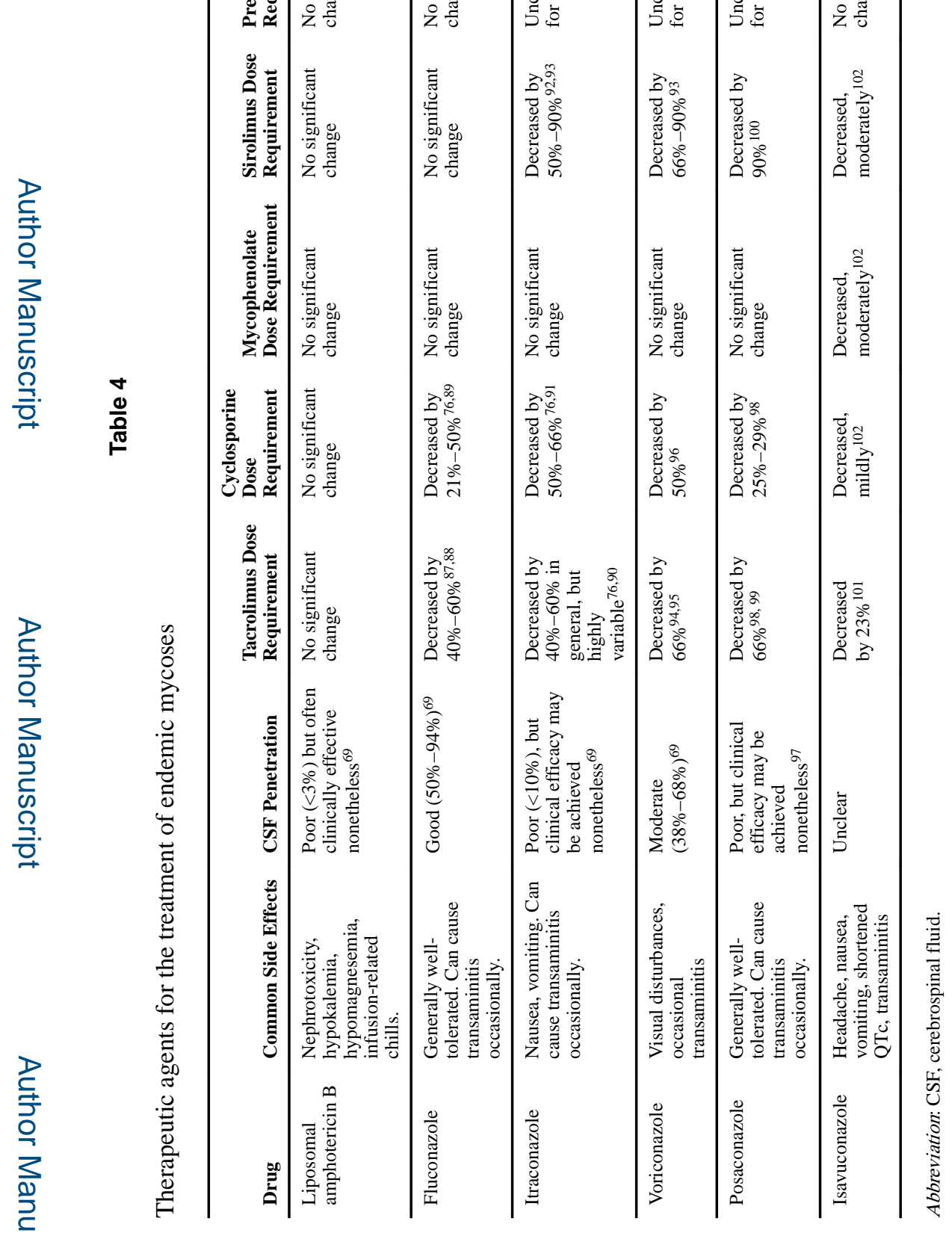

Infect Dis Clin North Am. Author manuscript; available in PMC 2019 September 01. 
Table 5

Suggested prophylactic regimens for endemic fungi in SOT recipients

\begin{tabular}{|c|c|c|}
\hline & Recipient Peritransplant Prophylaxis & $\begin{array}{l}\text { Secondary Prophylaxis } \\
\text { for Recipients After } \\
\text { Completion of Treatment } \\
\text { Course }\end{array}$ \\
\hline Histoplasmosis & $\begin{array}{l}\text { Donor with localized pulmonary } \\
\text { disease: itraconazole } 200 \mathrm{mg} \text { once or } \\
\text { twice daily for } 3-6 \text { mo } \\
\text { Donor with disseminated disease: } \\
\text { itraconazole } 200 \mathrm{mg} \text { once or twice } \\
\text { daily for } 12 \mathrm{mo}^{84}\end{array}$ & $\begin{array}{l}\text { Not routinely indicated. Can } \\
\text { monitor urine antigen level } \\
\text { every } 3 \text { mo to determine } \\
\text { need. If required, consider } \\
\text { itraconazole } 200 \mathrm{mg} / \mathrm{d} .{ }^{16,84}\end{array}$ \\
\hline Blastomycosis & $\begin{array}{l}\text { Donor with localized pulmonary } \\
\text { disease: itraconazole } 200 \mathrm{mg} \text { once or } \\
\text { twice daily for } 3-6 \text { mo } \\
\text { Donor with disseminated disease: } \\
\text { itraconazole } 200 \mathrm{mg} \text { once or twice } \\
\text { daily for } 12 \mathrm{mo}\end{array}$ & $\begin{array}{l}\text { Not routinely indicated. If } \\
\text { required, consider } \\
\text { itraconazole } 200 \mathrm{mg} / \mathrm{d} .{ }^{17}\end{array}$ \\
\hline Coccidioidomycosis & $\begin{array}{l}\text { Donor with isolated pulmonary disease: } \\
\text { fluconazole } 400 \mathrm{mg} / \mathrm{d} \text { for } 3-12 \mathrm{mo} \\
\text { (non-lung recipients) or lifelong (lung } \\
\text { recipients). } \\
\text { Donor with positive serology or } \\
\text { extrapulmonary disease: fluconazole } \\
400 \mathrm{mg} / \mathrm{d} \text { lifelong. }{ }^{84} \\
\text { Recipient with positive serology or } \\
\text { history of coccidioidomycosis: } \\
\text { fluconazole } 200 \mathrm{mg} / \mathrm{d} \text { for } 6-12 \mathrm{mo} . \\
\text { Recipient living in a } \\
\text { Coccidioides-endemic area: } \\
\text { fluconazole } 200 \mathrm{mg} / \mathrm{d} \text { for } 6-12 \mathrm{mo} .{ }^{59}\end{array}$ & $\begin{array}{l}\text { Fluconazole } 400 \mathrm{mg} / \mathrm{d} \\
\text { indefinitely. }{ }^{59}\end{array}$ \\
\hline
\end{tabular}

Abbreviation: SOT, solid organ transplantation. 